\title{
The Qualitative Interrelation between Open Spaces and Living Standards in a Residential Complex
}

\author{
Sepide Saiedlue *, Seyed Bagher Hosseini, Seyed Abbas Yazdanfar, Saeed Norouzian Maleki \\ School of Architecture and Environmental Design, Iran University of Science and Technology, Tehran, Iran
}

\begin{abstract}
From the early 50 s onwards the major Iranian cities were subject to a massive immigration. The immediate solution to this crisis was residential complex in the less populated areas. After few decades of accommodating a large number of new citizens in these residential complexes, while having a limited open space, created physical, functional, semantic, environmental, and social problems. Today, the new challenge that confronted the designers and architectures of this field is therefore how to improve the quality of both open spaces and the living condition of the inhabitances and at the same time being able to compete in the housing market with budgetary restrictions on their expenditures.
\end{abstract}

(C) 2016. The Authors. Published for AMER ABRA by e-International Publishing House, Ltd., UK. Peer-review under responsibility of AMER (Association of Malaysian Environment-Behaviour Researchers), ABRA (Association of Behavioural Researchers on Asians) and cE-Bs (Centre for Environment-Behaviour Studies, Faculty of Architecture, Planning \& Surveying, Universiti Teknologi MARA, Malaysia.

Keywords: Residential complex open space; open space factors; FANP

\section{Introduction}

Changes in social-demographic characteristics and cultural attitudes of urbanization in the early decades of the twentieth century led to increasing diversity in the housing market. These changes have a profound impact on the design for the construction of housing complexes (Einefar, 2001). Building large residential complexes about the period where one of the logical responses to the growing need for housing in the areas of rapid population. Social problems of low quality products of this category started in the early 70 s in the advanced industrial countries and therefore this concept was reviewed by many designers and experts in the field of architecture (Lang, 2005 \& Newman, 2006).

This study aims to improve the quality of the open space between the blocks of the residential complex, because the quality of open space between the blocks of the residential complex - which is also called the external environment - as well as the desirability of building projects directly related to the quality of life of their residents. Therefore, the validity of the idea and design of an open space in a residential complex not only depends on the quantity but more importantly on how the housing provided according to quality and accountability to enhance the quality of life.

Many architecture experts believe that in residential complex architecture, open space has received less attention. This created practical problems of users on one hand and the lack of proper coordination and communication between the residential

\footnotetext{
${ }^{*}$ Corresponding author. Tel.: +0-000-000-0000

E-mail address: sepideh.saiedlue@gmail.com
} 
quality of life and the environment on the other hand. The lack of quality infrastructure components such as green space, water, a place to exercise and walking, is the results of this inadvertence. The physical factors (functional) with impact, particularly on safety, impaired relaxation and comfort along with abnormalities in individual behavior and social relations between residents of housing complexes. Less attention to public open spaces in a residential complex as well as semantic factors of legibility and identity created doubt because it belongs thereby to the environment and social interaction in the context of its dysfunction. In addition, lack of attention to the public services in the building open spaces, in fact, distorts the urgent need of the residences to accelerate their daily life's movements and disrupted the transport system as well.

One of the main principles of architecture and Urbanism is a creation of favorable sensory and intellectual relationship between man and his environment (Waxman, 2004). Some experts believe that understanding and correct implementation of this relationship of designers can help promote links with their environment and as well as the other residents in urban areas to improve their social behavior.

Living in small apartments with limited space in a residential complex located at a distance from nature makes the home a place to relax, therefore, in this regard it is necessary to create public spaces for individuals and families according to that small housing conditions. For residential complexes about small apartments with limited resources and environmental quality which are not suitable a review of the design and the architecture has been the focus of many designers. One of the solutions that in the new architecture of eliminating the open house (yard) has been suggested is the creation of smaller spaces (balconies and terraces), respectively.

Living in the cities with high population density also makes impossible for the citizens to have an independent house with wide open spaces - such as Villa. Thus, the need for more research and find an appropriate solution in this field, alongside the residential areas, can obviously bring some answers to human needs and environmental quality. These complementary areas through some approaches for the development of indoor and outdoor spaces can bring a direct relationship between man and nature. More attention to creating open spaces as a place of exchanging ideas and learning social behavior, and as a result of good neighborliness between the citizens of a residential complex, can on the one hand to increase the participation of citizens in public open space and enhance the security of the social environment, and on the other hand bring an understanding of how to live in an environment which accountable to public as well as the environment.

This paper is trying to find the practical solutions to improving the quality of open spaces and also to show how to create an appropriate open space, according to the characteristics of the residential complex. This open space will be a place for gathering and coordination of the inhabitants, for exercise or running, for children to play. In the same way, other communal sites can also be shared with individual and collective which are the preconditions to provide comfort for the residents. The results of this study will show which factors have the greatest impact on improvement in the quality of residential space and what criteria should be applied in the design of public housing complexes in order to increase the quality of their open space.

Hypothesis One of the factors that increase the quality of the residential complex is the quality of open space.

This paper first will review the literature in the field of urban environment and the yard at the intersection of the two residential complexes which is the definition of open space. The open space in this regard will be similar to green open space in the city and open space in residential complex will be similar to the old yard, however, its application is not private use rather is for a group of residents in a complex, as a result, the factors in relation to the quality of the residential complex will be selected from the quality factors of the urban environment and yard.

\section{Review of the Literature}

\subsection{Urban environment}

The urban environment is not limited only to the physical city space or landscape, but also is a subject to the physical environment beyond the city which creates cooperation in the citizen's social, cultural, customs and traditions, and also encompasses bond between citizens. Oswald Spingler believes that the city is a mental realm, a place where tradition and customs and attitudes of individuals and organizations come together (Ghorab, 2001). The high-quality urban environment can meet the needs and comfort of a population in which they have resided (Paul, 1997). On the urban environmental quality components, many discussions have been raised. The most effective of them, which can be combined with the satisfaction with the relevant factors are those that created a sense of belonging or identity, as well as factors of legibility with citizens that create a sense of security and relaxation, sustain and renew the collective memory of people, the creation of historical identity and sense of belonging among the citizens, those in this article we will examine. Because the quality of the urban environment in the 
intellectual and emotional response that quotes Michael Gülen in his book "The perfection and power" tell us how the human psyche, the form, and its components take place (Mitchell Gülen, 2000). According to Lynch the citizens perceive urban environment only through understanding the visual perception of the quality of a city which is created by the citizens. The image and the perception that people had on their environment come through their feeling that is in its turn created by their environment.

The factors of quality of the human environment should give some comfort and attract the citizens of the area. Therefore, to create a quality environment in cities on the one hand, urban planners need to support the economic, social, and cultural aspects, on the other hand, policymakers and should also improve the quality of the urban environment in their urban planning. (Huang, 2006)

\subsubsection{Public open space}

Public spaces in the cities constitute the poor shape of the cities and are not fixed size of its position, change shape, and their stretch that in this way would attract the people to continue their activities on the town (Paknejad, 2009). Public space is a common place for citizens which are located in the general spaces in the cities and display the urban functional activities such as ritual ceremonies and celebrations put on public display (Madanipour, 2000).

Public space is a factor of a successful residential neighborhood where self-monitoring and social life takes place through space, and activities of daily continuity to create boundaries between public and private space (Mirgholaml, 2006). Social behavior is the dominant social and cultural characteristics of the public space, hence, the study of patterns of behavior that determines and indicates how public spaces are used should influence on the design and environmental planning in any given cities (Nozari, 2004). Residential open spaces are in fact crystallized the essence of the social life since these spaces and social interactions provide an opportunity for the citizen to meet each others in these spaces (Waxman, 2004).

On the quality of the urban environment Jane Jacobs in 1961 in his book "The Death and Life of Great American Cities" described that the most important issues to resolve anomalies in this regard are to apply the appropriate patterns of activity, the use of mixed methods, attention to the quality of the streets, permeability and flexibility of spaces. Lynch points of in his book "The Good City" in 1981 that to improve the quality of urban life depend on seven factors of happiness, meaning, adaptability, access, control, and efficiency of justice.Benteli \& El (1990) in "media respondent" has been drawn ten criteria, including permeability, variability, legibility, flexibility, visual adaptation, wealth, belongs to colors, with regard to energy efficiency, cleanliness and maintenance of ecosystems, as the norms that must be observed in urban design.

\subsection{The courtyard}

In "home, culture, nature" here defines the courtyard as the free space which people use for work, playing, and outdoor talking with liberty. He emphasizes that the courtyard is a comfortable room without a roof and pleasant space. He defines other open spaces in the house with Iranian-designed as non courtyard which includes a variety of open spaces with different heights (Haeri, 2009). The courtyard features are divided into three-part of physical, functional and semantic in a house. The physical part includes the geometry of the yard, combined space in the yard, privacy, closeness, hierarchy, and outlook. Climate, functional integration, naturalism, and social interaction are also other functions of a courtyard. 


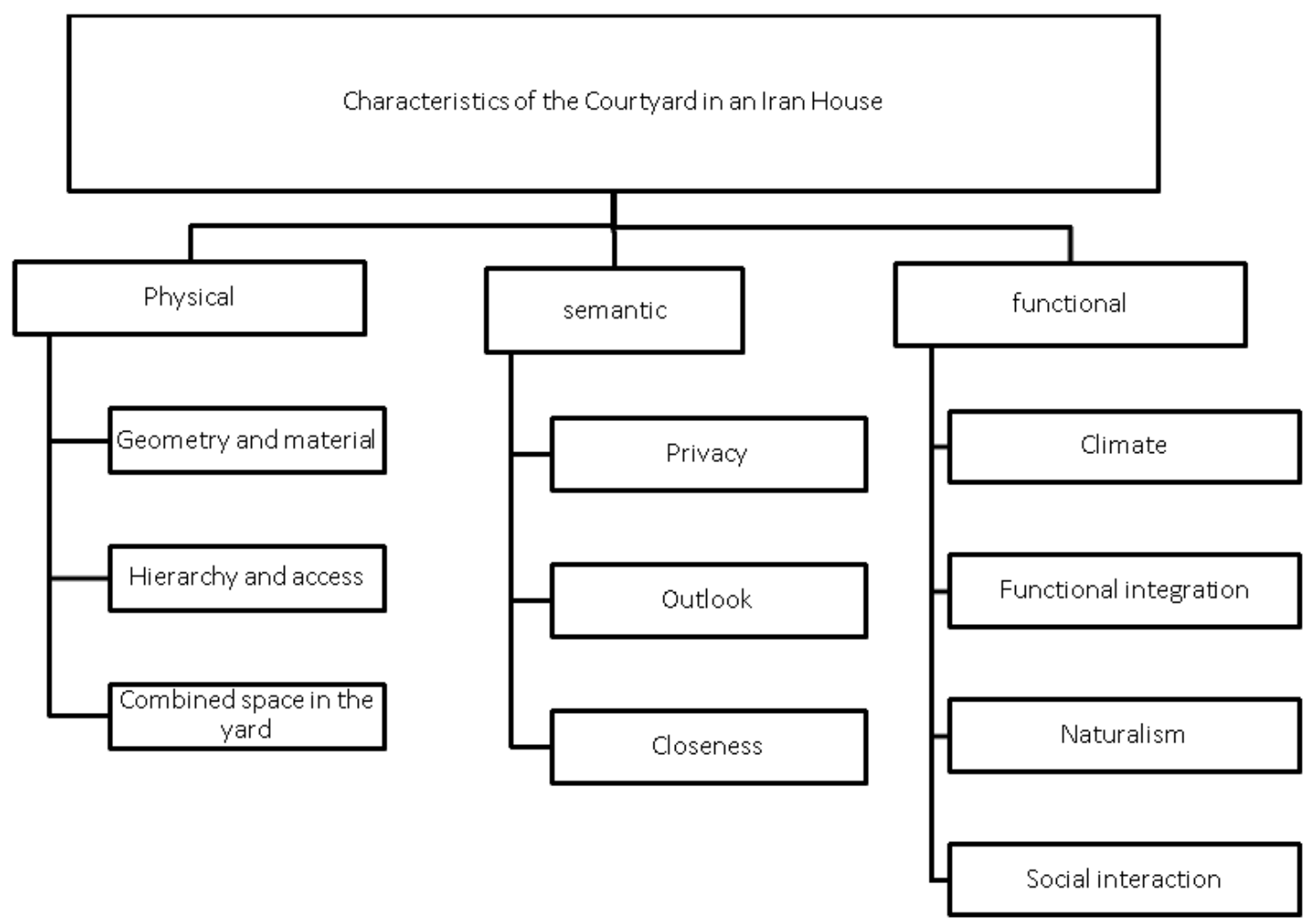

Fig 1. Characteristics of the Courtyard in an Iran House

Organization of space in a variety of houses is generally oriented toward the courtyard shaped geometry. The design of closed spaces or the indoors is often drawn around it. On the other hand, in the courtyard in the house space are designed for communication between people and nature as well as the community (Haeri, 2009). The geometry of the courtyard has often a regular order and is in the form of rectangular, which in the first stage of design gives feasibility for geometrical rectangular in the courtyard and in addition the pool and the garden also follow the same geometry.

The central courtyard is as the first space in the center and the second space where the main courtyard is there is in direct contact with it. The third space which is the border with the second space and the outer edges of the unit and has the role and the function of each space and size, shape, with respect to the main axes of the adjacent spaces, and create central space of the courtyard (Ghafari, 1994). Courtyard organizes the conditions set in such a way that its utilization is optimal and, in fact, has the role of controlling lighting directing at and controlling. The central courtyard in the structure has been designed in a way that makes the best use of air movement and the intensity of the heat and humidity inside the house (Aboullahzadeh, 2011).

\subsection{Definition of the open space in the residential complex}

The open Space area has been defined as a place without residences, personal ownership and is managed by the joint management of the units (Mohamedzadeh, 2011). Open space in a residential complex includes side spaces in the open fields, pathways for pedestrians and vehicles, green space, communal spaces, parking and permanent and temporary stations, landscapes, furniture, and directional boards. (Sun, \& Nashmira, 2005) referring to the definition of open space emphasis the surrounded or not surrounded areas and describes what open space has no building because the constructed space is made up of one-twentieth of the total space. The entire public space is for recreational purposes or remains unused (Mohamedzadeh, 2011).

The main role of open space in a residential complex is to adjust to the construction and human density. Providing appropriate levels in order to provide the necessary framework that allows them for activities which do not exist in an open space 
and to play partly as open space in a residential complex (Mohamedzadeh, 2011). In fact, open spaces designed to meet the needs of the residents of the neighborhood. Residential open space is a place for activities and human communication. Elements of residential open space include access routes for pedestrians and vehicles, green space, children's play areas, places to sit and rest temporarily (Nozari, 2004).

\section{Methodology}

\subsection{Research processes}

After reviewing the background of research subject and extracting the effective components in urban open space and the courtyard in houses, which has used the library and documentation texts, the model of classification of quality factors in the open space of the residential complex were prepared.

Table1. Quality Factors, and their Sub-Factors

\begin{tabular}{lllll}
\hline Social & Environmental & Semantic & Functional Factors & Physical Factors \\
Factors & Factors & Factors & & \\
\hline Social life & Relationship with & Vitality & Functional diversity & Building Size \\
Congruence & nature & legibility & Access to roads & Materials \\
Individual & Climate & Fixation & Economic & Human scale \\
Social & Cleanliness & Identity & Neighborliness & Geometry \\
Security & & Relaxation & Land and density & \\
& & Privacy & Vision and perspective & \\
& & Attribute & Flexibility & \\
& & (diagnosis) & Pecking order & \\
& quietness & Space for playing & \\
& Time & Access to & \\
& & Parking & \\
& & Permeability & \\
\hline
\end{tabular}

\subsubsection{Delphi Method}

After some theoretical studies and extraction of components affecting the quality of open spaces in residential complex, due to the large number of components and hence the impossibility of measuring them the Delphi method which is a structured method has been used. The group of decision makers, which consisted of six experts on PhDs and four experts with a master's degree in architecture and Urbanism planning has been selected. They have the task of the specification of the priority and importance of the factors which have been extracted and had to respond to them later on. Then, the number of factors has been refined and thus allows us for the measurement of samples.

\subsubsection{The network analysis (FANP)}

In order to obtain components which have the greatest impact on the quality of open space, residential complex the process network analysis based on the Saaty matrix method is used. The network analysis has flexible features, using simultaneous quantitative and qualitative criteria, and the ability to check the consistency of its judgments, and complex relationship (interdependencies and feedback) between and among the elements to be considered. ANP can be seen as consisting of two parts, first control hierarchy, and second network relationship. The hierarchy controlling consists of relationships between objective, criteria and sub-criteria, and has an effect on the internal communication system, and includes the networking dependencies on elements and requesting subjects (Zebardast, 1999). 


\subsection{Selecting residential complex sample (Case Study)}

In this study, Ekbatan residential complex (Phase Three) as well as the Hormozan residential complex had been selected and studied.

\subsubsection{Ekbatan residential complex (block E1)}

Ekbatan is one of the largest residential complexes in the Middle East which is located in the west of Tehran and in the six districts of the fifth municipality of Tehran. The surface of this complex is 5904 square kilometers and the number of its inhabitants is 430981 people.
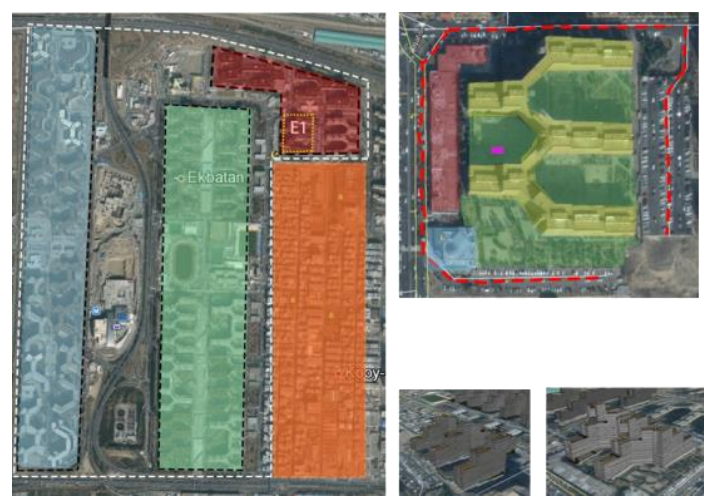

Fig 2. Ekbatan residential complex

\subsubsection{Hormozan residential complex}

Hormozan is one of the largest complexes in the Shahrak Gharb complexes. Its geographical location is in the Hormozan street phase 2 of the Shahrake Gharb in District of the second municipality. The area of these complexes is 11 acres and the numbers of residential units are 1269. The Omran Tklar Company built this complex.
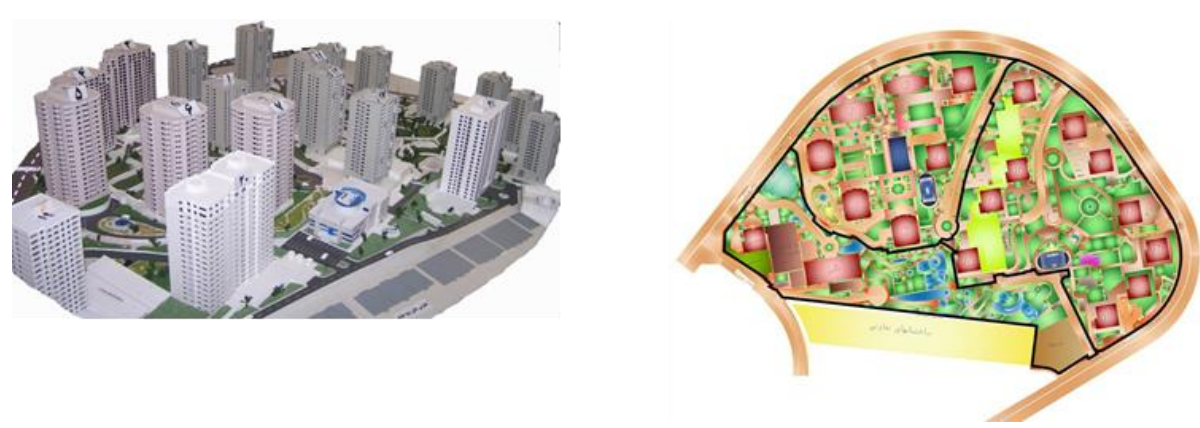

Fig 3. Hormozan residential complex 


\section{Findings}

\subsection{Information on population}

In order to collect data according to the formula sample of Klein (3.2 times the number of items) this study selected randomly 96 residents of the residential complex (54 from Ekbatan and 42 from Hormozan residential complexes. The responding information is presented in the charter below.

Table 2. An example of a table

\begin{tabular}{lllllllll}
\hline Complex & Gender & \multicolumn{3}{c}{ Ages } & \multicolumn{3}{c}{ Education } \\
\cline { 2 - 8 } & Women & Man & $29-20$ & $39-30$ & $49-40$ & $50+$ & Bachelor & Master \\
\hline Ekbatan & 45 & 9 & 6 & 15 & 22 & 11 & 43 & 11 \\
Hormozan & 29 & 13 & 3 & 16 & 16 & 7 & 12 & 30 \\
\hline
\end{tabular}

\subsection{Sampling}

Sampling was in clusters and the people is selected in different social, age, and gender groups. That was in order to select residences which were the representation as a whole.

\subsection{Delphi Findings}

In order for determine the characteristics of the quality of an open space, we considered thirty-two sub-factors for functional, physical, environmental, semantic and social factors. Due to the large number of factors and the complexity of their measurements, through the residences sample Delphi method has been used to reduce the sub-factors. Thus, the basic subfactors were placed in Table 4-1 which was selected by ten PhDs and Master degree in the field and experts of architecture and urban. The degree of importance of each indicator was considered from one to five and the experts have selected the factors of their priority and importance and finally some points were given to them. After collecting the factors the experts selected and calculated their average based on 3.2 to a high degree of importance and became the basis of the classification of those subfactors, and then on examining these sub-factors 21 finals of them for investigation were selected.

From 21 final sub-factors this researcher selected six sub-factors for functional factor, three sub-factors for physical factor, six sub-factors for semantic factor, three sub-factors for an environmental factor, and finally three sub-factors for the social factor.

Table 3. The sub-factors in this research with a priority to increasing the quality of an open space

\begin{tabular}{lllll}
\hline Social Factors & Environmental Factors & Semantic & Functional Factors & Physical Factors \\
& & Factors & & \\
\hline Social life & Relationship with nature & Vitality & Functional diversity & Materials \\
Congruence & Climate & Legibility & Access to roads & scale \\
Social & Cleanliness & Closeness & Neighborliness & Geometry \\
Security & & belonging & Vision and perspective & \\
& & Identity & Flexibility & \\
& & Relaxation & hierarchy & \\
\hline
\end{tabular}

\subsection{Responses from Ekbatan and Hormozan residential complexes}

Table 4 examines the questionnaires data. It shows how to control the rate of adjustment of each matrix, and then, in order to obtain a module matrix based on the paired comparison matrix, it uses the geometrical average. After calculation of the incompatibility, first the relative rate of factors are calculated, and then, in order to calculate the rate of indicators, it uses the 
Wang and Chine model. Unlike other models, this model calculate the rate based on Fuzzy model and shows the results in a framework of triangular fuzzy numbers, which is used for all components of Ekbatan and Hormuz residential complexes.

Table 4. Results of the sub-factors phase measurement of Ekbatan and Hormozan complexes

\begin{tabular}{|c|c|c|c|}
\hline Factors & Sub-factors & Ekbatan & Hormozan \\
\hline \multirow{3}{*}{ Physical } & Materials & (0/4، 0/57، & (0/82، 0/78، \\
\hline & Scale & (0/38، 0/27، 0/17) & (0/29، 0/21، 0/17) \\
\hline & Geometry & (0/59، 0/42، 0/27) & (0/61، 0/53، \\
\hline \multirow{6}{*}{ Functional } & Functional diversity & (0/2، 0/35، 0/35) & (0/1،0/13، 0/16) \\
\hline & Access to roads & (0/17، 0/14، 0/12) & (0/18، 0/26، \\
\hline & Neighborliness & (0/16، 0/13، 0/11) & (0/09، 0/06، 0/03) \\
\hline & Vision and perspective & (0/11، 0/08، 0/08) & (0/4، 0/37، \\
\hline & Flexibility & (0/33، 0/28، 0/21) & (0/14، 0/16، \\
\hline & Hierarchy & (0/5، 0/35، 0/216) & (0/53، 0/46، 0/38) \\
\hline \multirow{6}{*}{ Semantic } & Legibility & (0/08، 0/08، (0/12) & (0/12، 0/17، 0/22) \\
\hline & Closeness & (0/33، 0/28، 0/21) & (0/61)، 0/5، \\
\hline & Belonging & (0/26، 0/23، 0/22) & (0/46، 0/39، 0/33) \\
\hline & Vitality & (0/16، 0/13، 0/11) & (0/24، 0/19، \\
\hline & Identity & (0/2، 0/35، (0/35) & (0/2، 0/12، 0/09) \\
\hline & Relaxation & (0/17، 0/14، 0/12) & (0/53، 0/66، \\
\hline \multirow{3}{*}{ Environmental } & Cleanliness & (0/85، 0/81، 0/73) & (0/11، 0/13، 0/16) \\
\hline & Climate & (0/26، 0/18، 0/14) & (0/12، 0/14، \\
\hline & Relationship with nature & (0/5، 0/64، 0/73) & ) \\
\hline \multirow{3}{*}{ Social } & Social life & (0/36، 0/5، 0/63) & (0/4، 0/57، 0/72) \\
\hline & Social Security & (0/17، 0/13، 0/11) & (0/2، 0/35، (0/35) \\
\hline & Congruence & (0/25، 0/35، 0/25) & (0/17، 0/14، 0/12) \\
\hline
\end{tabular}

\subsection{The final measurement of the criteria and sub-criteria and indicators}

In Ekbatan residential complex environmental factor is the most effective factor of improving the quality of open space. Then it follows with social, physical, functional, and semantic factors. In Hormozan residential complex, the most effective factor is an environmental factor of improving the quality of open space. Then it follows with social and semantic factors. 
Table 5. An example of a table

\begin{tabular}{lll}
\hline Factor & Ekbatan priority & Hormozan priority \\
\hline Functional & 4 & 5 \\
Semantic & 5 & 3 \\
Environmental & 1 & 1 \\
\hline Social & 2 & 2 \\
\hline Physical & 3 & 4 \\
\hline
\end{tabular}

In Ekbatan residential complex about the context of a physical factor the diversity of users and services, flexibility and hierarchy are the most effective sub-factors in improving the quality of the open space. In Hormozan, residential complex vision and perspective sub-factors are the most affecting components for improving the quality of the open space. In Ekbatan, residential complex vitality sub-factor in the context of a semantic factor is the most effective component. In Hormozan residential complex relaxation and belonging to the context, the semantic factor is the most important components. In Ekbatan, residential complex sub-factor of contact with nature is the most important component in the improvement in the quality open space.

Table 6. Results of the sub-factors phase Prioritized of Ekbatan and Hormozan complexes

\begin{tabular}{|c|c|c|c|}
\hline Factors & Sub-factors & Prioritized Ekbatan & Prioritized Hormozan \\
\hline \multirow{3}{*}{ Physical } & Materials & 2 & 2 \\
\hline & Scale & 1 & 3 \\
\hline & Geometry & 3 & 1 \\
\hline \multirow{6}{*}{ Functional } & Functional diversity & 1 & 5 \\
\hline & Access to roads & 4 & 3 \\
\hline & Neighborliness & 5 & 6 \\
\hline & Vision and perspective & 6 & 1 \\
\hline & Flexibility & 2 & 4 \\
\hline & Hierarchy & 3 & 2 \\
\hline \multirow{6}{*}{ Semantic } & Legibility & 4 & 5 \\
\hline & Closeness & 2 & 4 \\
\hline & Belonging & 3 & 2 \\
\hline & Vitality & 1 & 3 \\
\hline & Identity & 5 & 6 \\
\hline & Relaxation & 6 & 1 \\
\hline \multirow{3}{*}{ Environmental } & Cleanliness & 2 & 2 \\
\hline & Climate & 3 & 3 \\
\hline & Relationship with nature & 1 & 1 \\
\hline \multirow{3}{*}{ Social } & Social life & 1 & 3 \\
\hline & Social Security & 3 & 2 \\
\hline & Congruence & 2 & 1 \\
\hline
\end{tabular}


In Ekbatan residential complex about the context of the social factor, the sub-factors of social life and congruence have the most impact on quality of open space. In Hormozan residential complex, the most effective sub-factor in the context of an environmental factor is contact with nature. In Ekbatan residential complex about the context of a physical factor, the sub-factor scale has an important effect on the quality of open space. In Hormozan residential complex, the sub-factor geometry in the context of a physical factor has important effects on quality of open space.

\section{Results and Perspectives}

The purpose of this paper is to examine and explain the practical guideline to improve the overall quality of open spaces in the residential complex. Therefore, after studying two residential complexes of Ekbatan and Hormozan the results for improving the quality of open spaces can be formulated as Follows.

- The quality of a residential complex is a condition (and a term) which one may characterize or describe with two sets of five essential different but interrelated factors. The first set is a physical, one in which quality differs from what they have fundamentally been and also what improvement they were capable of generating came from its sub-factors such as materials, scales, and geometry. The second is an inclusive set which consists of four different factors that include functional, semantic, environmental, and social which in a traditional residential complex had originally been static or even stagnant -incapable of gen

- erating improvement from traditional design concept and practices - but over the course of time and for various historical reasons - urbanization, cultural improvement, climate change, and socialization - this set became subject to the impact on one or more modern architectural concept and designs. In fact, quality improvement becomes a fundamental characteristic of the residential complex when the interrelation between physical factor and other factors (functional, semantic, environmental, and social) became crucial to an understanding of conceptual modernization. Ekbatan and Hormozan residential complexes, by virtue of their necessity for a quality improvement in their open spaces, became the subject of the case study for this research.

- Improving the quality of the open spaces will bring crucial changes in the living standards of the residents in Ekbatan and Hormozan residential complexes. This improvement could eventually bring a new form of urban development while considering the quality of the residential complex based on physical, functional, semantic, environmental, and social factors. If referred to their responses to questionnaires which were distributed, the impact on this improvement shall help the most residents to become familiar with the new design and approaches, as well as create new comparative norms for open space in their residential complexes. This quality orientation for design deficiency can be satisfied with "Persian Garden" because in all responses to both case studies in these two residential complexes the lack of environmental factors could be observed. In this respect, the need for a new design and in order to improve the quality of open space the following subfactors are Encouraged.

- The interrelations between improving the quality of open space and residents' quality of life in residential complexes in the first step bring our design towards the search and recognition of some aspects of the quality factors which are partly the base of their requests, because in this way a feasible reconstruction plan for designer will be crystallized. This first requires the improvement in physical factors and sub-factors which should be added to design and plan of development. However, that alone is not sufficient to bring quality improvement for residents if at the same time other factors are not taken into account. This will create a challenge to the designer and a question that how to improve the quality of both open space and living conditions and at the same time competing with the housing market with restrictions on the expenditure. A reasonable method to confront this challenge is to consider the second set of factors of a social capital along the financial and material investment. That means, in fact, to follow the construction market, while a variety of human materials and services are in addition considered as the added value.

- An appropriate design to improve the quality of life for residents in the residential complex should include the tastes and demands of the people by using all quality factors in order to be held accountable. For this reason, the semantic factor and its sub-factors such as vitality and legibility, not only make the faces of the complex realistically convenient, but also improve the quality of life for residents in a smooth arrangement. By adding an environmental factor of design, in fact, the improvement in the quality of the open space will enter into a new stage of modern construction. That means a form of traditional architecture and a different design for open space with attention to the aesthetics of the building shall come together alongside the integration of human contacts with nature as a whole. Social factor and its sub-factors in the design provide cultural homogeneity and social security. Open space, admittedly, is a place for social relations while it is necessary 
that the security of the residents was considered as a priority in the design since it enhances the quality of life and living standards.

In addition to the above five major factors, some of the important residential complex based on sub-factors play a crucial role in the design of open space in a residential complex. At first place is the basic functional needs of the inhabitants such as children play-ground and leisure space for seniors should be identified and designed. It is also important to design appropriate access routes with the target of increasing communal gathering and bring interests in citizens in order to satisfy the physical and spiritual needs of the residential complex inhabitances.

\section{References}

Aboullahzadehzadeh, S. M. ( 2011). Consistent with the nature of traditional Iranian architecture, Village Magazine, No. 70, Tehran. Bentley, et al. (1990). Responsive environments, book designers (M Behzadfar, Translator). Tehran's University of Science and Technology Center. Chung, S.H. Lee, A.H.L. Pearn, W.L. (2005). Analytic network process (ANP) approach to product mix planning in semiconductor fabrication, International Journal of Production Economics, 96, 15-36.

Einefar, A.R. (2001). Analysis of the relationship between physical design and experience in residential neighborhood, Virtual, 1(1), $28-40$.

Einefar, A.R., Ghazizadeh S. N (2010). Typology of Residential Tehran with open standards. Architecture and Utopia: Winter 1389, 3(5), 35-45.

Ghorab, D.A. (2001). The effects of human alienation in the urban environment, Urban Management Journal, 8.

Ghaffari century, A. (1371). The principles of consecutive spaces in urban architecture, platform, Year 2, Issue 6

Haeri Mazandaran, M. (1388). The House of Culture of Nature, Tehran, Center for Urban and architecture research, printing.

Huang, S. (2006) . A study of outdoor interactional spaces in high-rise housing, Landscape and Urban Planning, 78, 193-204.

Jencks, C. (1985). Modern Movements in Architecture, Penguin Books, Baltimore .

Lang, J. \& Moleski, W. (2010). Functionalism Revisited: Architectural Theory and Practice and the Behavioral Sciences. Ashgate Publishing, Farnham

Madanipoor, A. (1379). The design of the urban environment, social and spatial vision process, translated by F. Mortezai, Tehran, processing and urban planning, August 1379.

Mahmoodi, A., Ghazizadeh. S, N. \& Mona. A, R. (2011). The Impact of the Architectural Design on the Thermal Comfort of the Outdoor Spaces in Residential Complexes* Case Study: Ekbatan Complex, Phase III. Journal Fine Arts and Architecture, 2(42), 59-70.

Mitchell, G. (2000). Indicators as tools to guide progress on the sustainable development pathway. Sustaining human settlement: $A$ challenge for the new millennium, 55-104.

Mohammadzadeh, R. (2012). Assessment of Spatial and Physical Factors Quality of Sahand New Town Residential Communities Open (Outdoor) Spaces. Journal Fine Arts and Architecture, 3(47), 29-38.

Newman, O. (2006). Defensible Space: People and Design in the Violent City, London, Architectural Press.

Nozari, S. (1383). Open Space Residential Design Guidelines, year 14, No. 39.

Pakzad, Jahānšāh (2009). Syrandyshh in urban (III), Tehran: Shahidi

Waxman, lisa kinch (2004). More than coffee : an examination of people, place and community with implications for design . ph.D. thesis, florida state university Zebardast, E. (2011). The Application of Analytic Network Process (ANP) in Urban and Regional Planning. Journal Fine Arts and Architecture, 2(41), 79-90. 